九州大学学術情報リポジトリ

Kyushu University Institutional Repository

\title{
Air-Conditioning Load Characteristics and Peak Reduction Potential for Demand Response in A Residential Community
}

Lyu, Jiajun

Interdisciplinary Graduate School of Science Engineering (IGSES), Kyushu University

Hagishima, Aya

Interdisciplinary Graduate School of Science Engineering (IGSES), Kyushu University

Tanimoto, Jun

Interdisciplinary Graduate School of Science Engineering (IGSES), Kyushu University

https://doi.org/10.5109/4738554

出版情報: Proceedings of International Exchange and Innovation Conference on Engineering \& Sciences (IEICES). 7，pp. 26-31，2021-10-21. 九州大学大学院総合理工学府

バージョン:

権利関係: 


\title{
Air-Conditioning Load Characteristics and Peak Reduction Potential for Demand Response in A Residential Community
}

\author{
Jiajun Lyu $^{1 *}$, Aya Hagishima ${ }^{1}$, Jun Tanimoto ${ }^{1}$ \\ ${ }^{1}$ Interdisciplinary Graduate School of Science Engineering (IGSES), Kyushu University \\ 816-8580, Japan \\ *Corresponding author email: carllv0629@gmail.com
}

\begin{abstract}
The residential air-conditioning load (ACL) has been identified as a key contributor to demand peaks, especially in the summer season. Occurrence of such intensive electricity loads has been a challenge for generation and transmission networks to ensure the necessary supply capacity. However, the comprehensive analysis of the characteristics of residential $A C$ use in the real community has been hampered by the limited availability of appliance level interval consumption data. This study used appliance level data measured by smart meters in a residential community of 586 households in Osaka, Japan, to evaluate the contribution of the ACL to the total demand peak in the summer season. The target households were classified into several groups based on their cooling usage preferences and introduced into two different demand response (DR) scenarios. The DR potentials for each group of households were compared to assess the peak reduction effectiveness in not only the whole community but also different groups of customers.
\end{abstract}

Keywords: Air-conditioning load (ACL); Load flexibility; Peak reduction; Demand response; Residential community

\section{Introduction}

The air-conditioning load (ACL) is one of the key contributors to residential electricity demand, accounting for $28.6 \%$ of residential energy consumption in Japan in 2018 [1]. In addition to the total energy consumption, the ACL has a strong influence on the seasonal variation in electricity demand as well as the occurrence of the annual peak demand [2]. The annual peak electricity usage usually occurs and lasts for several successive hours in the summer season with intensive cooling demand. Owing to the supply capacity for these occasional peak demands, power suppliers have been facing challenges such as the proper coordination of the scheduled maintenance of generators in the peak period [3]. Generation and transmission networks are also expected to increase the capacity and investment necessary to match the occurrence of the peak demands. Adnan et al. [4] applied a self-administered questionnaire targeting 123 households in Rafah, indicating that residents are aware of energy conservation in residential buildings and have a good attention to achieve reduction in energy demand. Murtyas et al. [5] investigated the energy consumption in a hotel in Indonesia and found that occupants' using behaviour of HVAC system and other devices were dominantly affecting the total electricity demand.

Regarding the influence of heating ventilation and cooling (HVAC) on the peak demand, various studies focusing on both commercial and residential sectors have been conducted in various regions. For example, commercial cooling use accounts for over $40 \%$ of the annual peak electricity load in California, USA [6]. Rosenthal et al. [7] evaluated the effects of climate change on energy use in the United States and estimated a $15 \%$ increase in commercial buildings and $20 \%$ for residential buildings with an increase in daily air temperature of $1{ }^{\circ} \mathrm{C}$. Scott et al. [8] reported that increases in commercial space cooling energy consumption with increasing temperature are less sensitive compared to the residential sector. Fan et al. [9] analysed the residential electricity demand data of Australia's largest smart grid and suggested that a $10 \%$ increase in households with ducted air conditioners (ACs) leads to a 9\% growth in the annual peak demand.
Drysdale et al. [10] pointed out that an increase in the peak demand caused by an increase in the residential ACL has led to continuous growth in traditional generation plants, which is neither sustainable nor economical, causing an increase in fossil fuel consumption and carbon emissions. Therefore, flexibility of the ACL in electricity demand has recently received increasing attention for effective approaches to the demand response (DR). The DR is gaining increasing attention as an advanced demand-side energy management strategy. Based on the price or incentive signals while ensuring customers' energy utility, DR provides a promising alternative for flattening the intensive energy consumption and avoiding the generation and network argument due to the supplydemand imbalance $[11,12]$.

Substantial research efforts have been made to link the DR with residential AC usage to incentivize occupants for potential AC load shifting and peak demand reduction. Several studies have been conducted on the flexibility quantification of air-conditioning systems for different ambient temperature conditions or operation setpoints [13,14]. Additionally, Zhang [15] and Kwac [16] reported that curtailing or temporally turning off the AC for a short period for the DR does not significantly aggravate the thermal comfort of the occupants. Cole et al. [17] examined the potential of the coordinated control of residential AC systems for peak electricity demand reduction. For the simulated community, it appeared that large energy and cost savings could be achieved by applying the proposed dynamic pricing control during peak hours. Koutitas [18] reported that over 25\% savings in peak demand consumption can be achieved by increasing the temperature threshold of the room from $1{ }^{\circ} \mathrm{C}$ to $3{ }^{\circ} \mathrm{C}$. Xue et al. [19] proposed an interactive demand-management strategy based on precooling and thermal storage. Intensive ACL at peak hours can be avoided to significantly reduce the imbalance between power supply and demand. Hu et al. [20] used a grey-box model to estimate the DR potential of residential AC under different control strategies in Hong Kong. This indicates that during a 2-hour DR event, increasing the $\mathrm{AC}$ cooling set-point temperature by $1{ }^{\circ} \mathrm{C}$ results in a 
peak demand reduction of $25 \%$. Furthermore, precooling $1 \mathrm{~h}$ before the DR event and increasing the AC cooling set-point temperature by $1{ }^{\circ} \mathrm{C}$ reduces the peak demand by $31 \%$. Nevertheless, several studies have pointed out that DR control strategies often induce an energy rebound effect or a new peak after the DR period has ended when ACLs appear to increase in order to return the thermal zone to the desired level [12,21].

The estimation of the DR potential in ACL in most research is based on assumptions of the customers' participation in the scale of the entire community. However, the benefits of the involvement of prioritised or partial consumers for DR in a real community have seldom been investigated. The effectiveness of the peak demand reduction for various consumers with diverse AC use preferences has also been overlooked in studies on DR feasibility by AC control. Most of the abovementioned studies focused on the DR potential of ACL using household-level electricity demand data other than appliance-level data. Considering that the stochastic nature of the ACL is directly proportional to the diverse occupant behaviours and preferences, analysis based on appliance-level demand data, which enables tracking of occupants' behaviour, is necessary.

To overcome the abovementioned limitations, the present work was conducted using electricity data from over 400 households, including appliance-level consumption with 1-min intervals. The objectives of this study are as follows:

- To evaluate the contribution of ACL to household electricity consumption in real residential dwellings

- To identify the stochastic nature of occupants' AC use behaviour among different households

- To assess the flexibility of the AC load for reduction potential in annual peak demand by applying different DR control methods.

- To evaluate the effectiveness of DR control with both community-scale and partial participation in households with different usage habits.

The remainder of the paper is structured as follows. Section 2 presents the outline of the dataset and the necessary data treatment process. Section 3 covers the statistical analysis results of the total demand data and ACL. Section 4 discusses the DR potential for the peak load reduction considering different DR control scenarios. Section 5 presents an overall conclusion and discussion of the present study.

\section{Dataset outline}

2.1 Description of surveyed building and community

The electricity consumption database used in the present study was obtained from a 20-story residential building located in Osaka. Tables 1 and 2 present a summary of the database and target building. The building consists of 586 dwelling units and an energy consumption of 18 branches. The appliance level consumption of each branch was recorded for each dwelling at 1-min intervals between January and December 2013. Using this dataset, we identified the electricity consumption of all the room air conditioners installed in the target dwellings.

The dwellings comprised two to four bedrooms, one living and dining room connected to the kitchen.
Regarding the building envelope, multiple insulation layers, including polyurethane foam and an air-filled cavity, were applied on the building's external walls. The same type of AC manufactured by the same company was installed in the living room of all the surveyed dwellings during construction. The annual performance factor (APF) of these ACs ranged from 4.7 to 6.7, depending on the floor area. In contrast, the AC installed in the bedrooms was purchased and installed by each resident. Information on the family composition, occupation, gender, and age of each dwelling was not disclosed because of privacy protection.

Table 1. Outline of energy demand data

\begin{tabular}{|c|c|}
\hline $\begin{array}{l}\text { Measurement } \\
\text { items }\end{array}$ & $\begin{array}{l}\text { Electricity of total and } \\
\text { breakdown consists of } 18 \\
\text { branches in each dwelling. }\end{array}$ \\
\hline $\begin{array}{l}\text { Minimum } \\
\text { measurement unit }\end{array}$ & $0.017 \mathrm{~W}$ \\
\hline $\begin{array}{c}\text { Measurement } \\
\text { period }\end{array}$ & $\begin{array}{c}1 \text { January } 2013 \sim 31 \text { December } \\
2013\end{array}$ \\
\hline $\begin{array}{l}\text { Measurement } \\
\text { interval }\end{array}$ & $1 \mathrm{~min}$ \\
\hline
\end{tabular}

Table 2. Outline of target residential community

Location Settu City, Osaka, Japan

Number of stories 20

Completion date

January, 2011

Structure

Reinforced concrete structure

Building

envelopes

External walls: internal insulation with air layer, U-value 0.441 $\mathrm{W} / \mathrm{m}^{2} \mathrm{~K}^{1}$

Windows: Low-E double-glazing Total 586 dwellings

Number of 38 dwellings: 2LDK

dwellings 391 dwellings: 3LDK 157 dwellings: 4LDK

A part of the dwelling units of the original dataset includes missing values, a long absence of occupants, and other measurement errors. Thus, a data cleaning process was conducted to exclude invalid data from households with the above problems and to reduce the original 586 households to 518 . With pre-installed AC in the living room and self-installed AC in bedrooms, this analysis included a total of $1398 \mathrm{AC}$ units as the main target.

\subsection{Meteorological condition in target period}

For the investigated period from January to December 2013, the dry bulb temperatures observed at the Toyonaka weather station of the Automated Meteorological Data Acquisition System (AMeDAS) were used for the analysis. AMeDAS is a high-resolution surface-observation network system developed by the Japan Meteorological Agency for collecting regional weather data. Considering that the distance between the weather station and target building was $10 \mathrm{~km}$, the influence of it on the accuracy of meteorological parameters is negligible. 
Table 3. Summertime temperature and sunlight hours of target region in 2013

\begin{tabular}{cccc}
\hline Year & Month & $\begin{array}{c}\text { Average } \\
\text { temperature }\left[{ }^{\circ} \mathrm{C}\right]\end{array}$ & $\begin{array}{c}\text { Hours of } \\
\text { sunlight }[\mathrm{h}]\end{array}$ \\
\multirow{2}{*}{2013} & Jul & 28.2 & 222.5 \\
& Aug & 29.7 & 255.9 \\
& Sept & 24.9 & 210.7
\end{tabular}

Fig. 1 shows the annual variation in the daily average, maximum, and minimum outdoor air temperatures in Osaka in 2013. A distinct seasonal cycle can be observed, in which the outdoor air temperature rose from July to August and then a lower level was experienced from December to January. The peak temperature occurred in mid-August at $39.8{ }^{\circ} \mathrm{C}$, and the lowest level of $-3.7^{\circ} \mathrm{C}$ was recorded in mid-February. Information on the summertime temperature and sunlight hours is presented in Table 3.

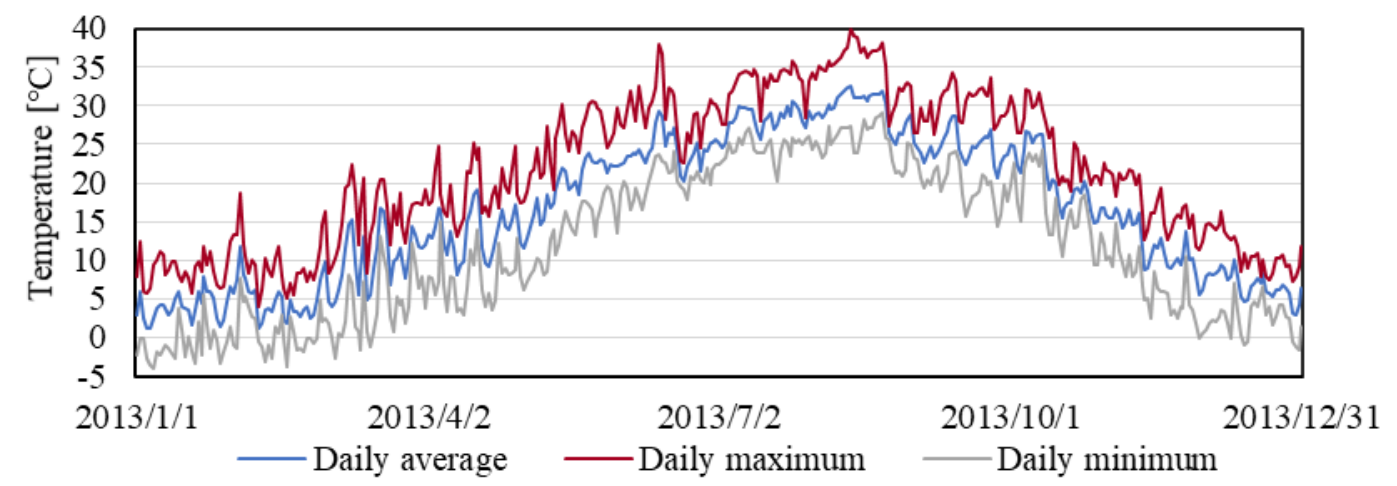

Fig. 1. Annual variation in the daily average of outdoor air-temperature in Osaka

\section{Load data analysis}

\subsection{Aggregated load characteristics}

Fig. 2 shows the seasonal variation in the statistical distribution of electricity demand aggregated for the target community. The community's median load is larger in winter (December to February) and summer (July to September), showing over approximately 200 $\mathrm{kW}$ compared to the spring and autumn seasons with a median level of approximately $150 \mathrm{~kW}$. The monthly maximum of the aggregated load is higher in the cooling season than in the heating season, with an annual peak of above $400 \mathrm{~kW}$ in August. It should be noted that the interquartile range of the load also appears to be larger in winter than in summer. This large variation in winter may be caused by the diversity of the dependence on ACs as a heating measure among households in the residential building, which is equipped with a gas floor heating system in addition to room air conditioners.

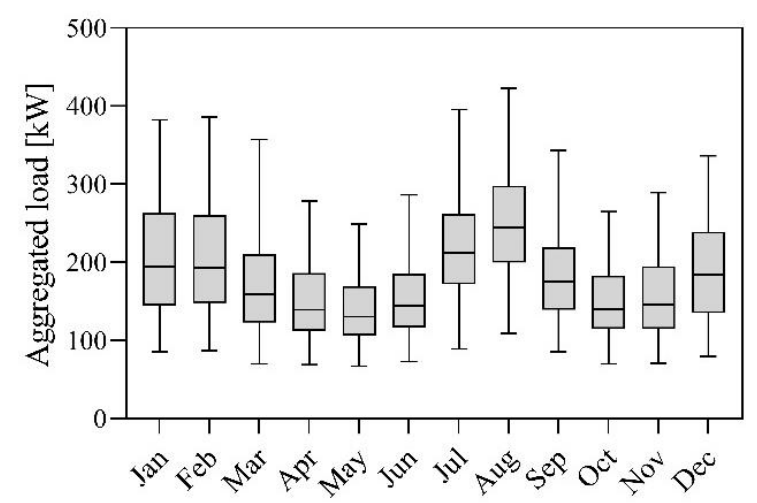

Fig. 2. Box plot of aggregated load in each month

For the following analysis of the DR potential of the ACL we utilised the 2.5 th percentile of the aggregated demand $(332.1 \mathrm{~kW})$ as a threshold to determine the annual peak duration, which requires DR. Fig. 3 shows the occurrence of the peak duration and number of days with the peak duration (hereafter, peak days) in each month. This suggests that most of the peak duration occurred in
January, February, July, and August. Particularly, the two months exhibit a much higher frequency of the peak duration occurrence.

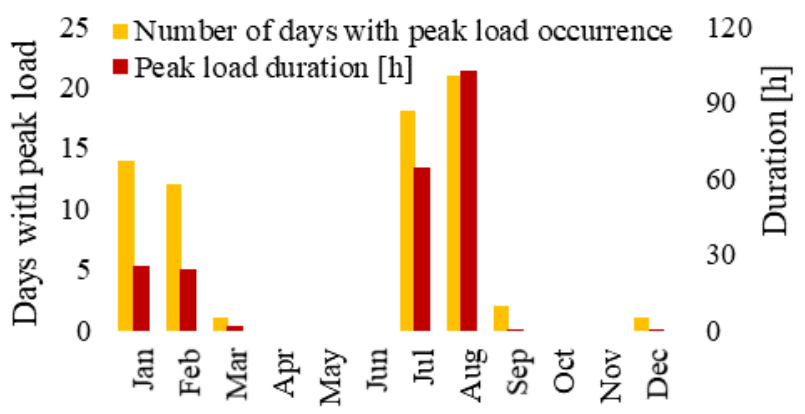

Fig. 3. Number of days with peak load occurrence and peak load duration for each month

\subsection{Stochastic features of ACL}

Considering that July and August have longer peak durations than the winter months, the authors focused on the analysis of ACL for cooling in the summer season. First, to evaluate the contribution of the summer season ACL to household electricity consumption, an analysis of both the AC and household overall load profiles was conducted.

Fig. 4 shows a scatter plot of the ACL and total household load during the peak load days in August. The total load ranged between $300 \mathrm{~W}$ and $800 \mathrm{~W}$; in contrast, the ACL fluctuated from $60 \mathrm{~W}$ to $350 \mathrm{~W}$. A positive correlation can be clearly observed between the ACL and total demand, which suggests the strong influence of the residential airconditioning load on the summer peak. In fact, during peak hours, the share of the ACL in the total demand exceeded $50 \%$. This large contribution of the ACL on the peak demand implies the effectiveness of the DR control of AC cooling use. 


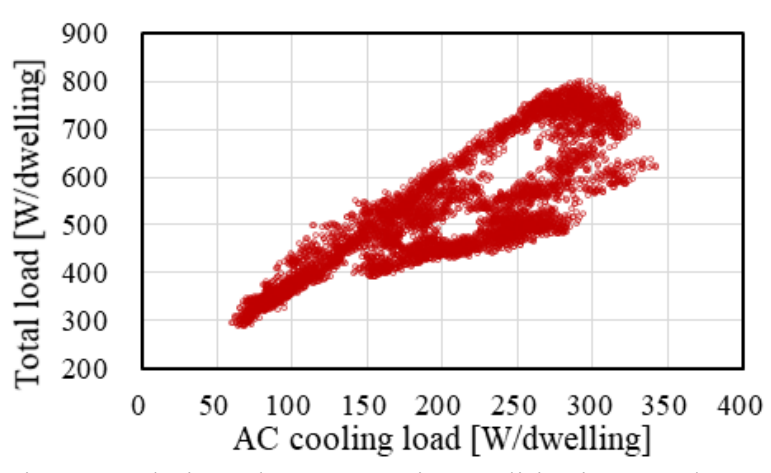

Fig.4. Relation between air-conditioning and total household loads during peak load days in August 2013

Based on the energy data with 1-min intervals, all sequences of the continuous AC load profile started by switching on and ended by switching off were identified throughout the summer season. These profiles consist of the switching on/off time, duration of cooling use, and electricity consumption for each event. Fig. 5 shows the scatter plot for the daily number of households' AC cooling events and daily electricity consumption throughout the summer. Most of the evaluated households had a diversity within 80 to 120 cooling events, indicating approximately one AC use per day. The AC cooling consumption for each household varied from 0 to $500 \mathrm{kWh}$. Fig. 6 shows the hourly probability of the AC cooling use in the summer season for all the target households. The probability patterns were compared between the AC use during the entire summer and peak load days. Two peak periods of the AC cooling use frequency can be observed at around 8AM and 1921PM, with more frequent $\mathrm{AC}$ use in the evening peak. Furthermore, compared to the overall pattern for the entire summer, AC use among all the households appears to be more intensive in the peak load days, with a higher probability in the evening peak period.

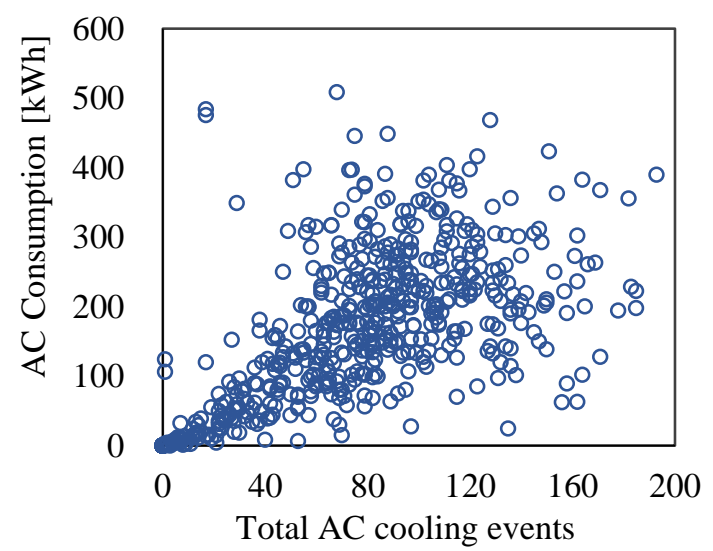

Fig.5. Relation between number of AC cooling events and $\mathrm{AC}$ electricity consumption throughout the summer season for each household

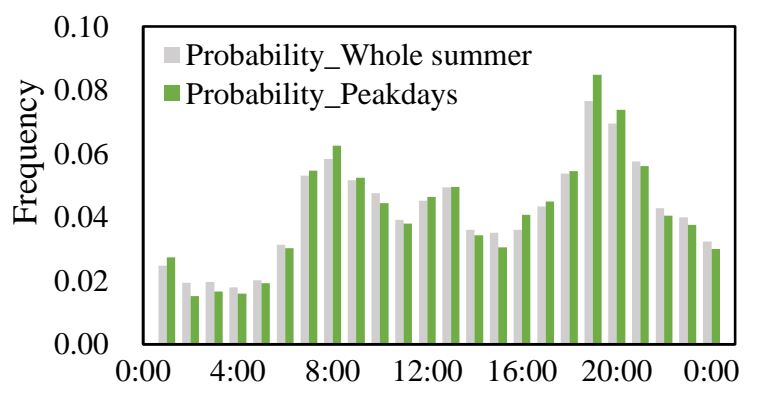

Fig.6. Hourly probability of AC cooling use in summer season for all households

\section{Peak demand reduction potential \\ 4.1. Classification of dwellings}

To estimate the effectiveness of the DR through AC control for the annual peak reduction under different conditions in terms of the fraction of households involved in the DR, the households were classified according to the total AC usage hours throughout the summer season. As presented in Table 4, the total community consisting of 528 dwelling units was classified into six groups. Group 1, in contrast was identified as having the least reliance on AC cooling in summer, with a total cooling time of less than $200 \mathrm{~h}$. Group 6, on the other hand, included 57 households with the longest hours of $\mathrm{AC}$ use.

Table 4. Classification results of the target dwellings based on the cooling hours throughout the summer season

\begin{tabular}{cccc}
\hline Group & $\begin{array}{c}\text { Total AC } \\
\text { hours [h] }\end{array}$ & Dwellings & $\begin{array}{c}\text { Dwelling's } \\
\text { fraction }\end{array}$ \\
\hline 1 & $0 \sim 200$ & 82 & $15.5 \%$ \\
2 & $200 \sim 400$ & 93 & $17.6 \%$ \\
3 & $400 \sim 600$ & 117 & $22.1 \%$ \\
4 & $600 \sim 800$ & 115 & $21.8 \%$ \\
5 & $800 \sim 1000$ & 64 & $12.1 \%$ \\
6 & $>1000$ & 57 & $10.8 \%$ \\
\hline
\end{tabular}

A violin plot of the distribution patterns of the $\mathrm{AC}$ electricity consumption throughout the summer in all six groups is shown in Fig. 7. The dotted lines indicate upper and lower quartile level and median level is shown by the solid line. An increase in the household-level cooling consumption was observed, as expected from groups 1 to 6. It is noteworthy that the dwellings in group 6 exhibited greater diversity in the cooling usage. This can be explained by a more frequent switching on/off and more diverse cooling use under different weather condition for the active AC users in group 6.

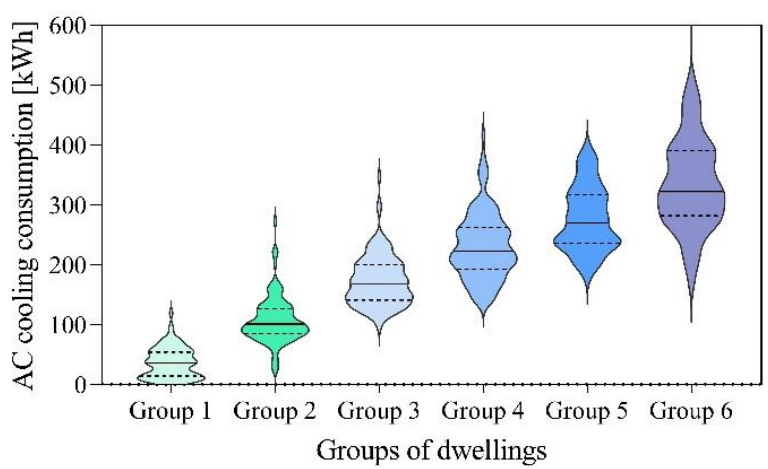

Fig. 7. Violin plot of AC consumption distribution in each group of dwellings

\subsection{DR scenarios for potential peak load reduction}

To quantify the effectiveness of the demand response in the load shifting and potential peak load reduction, two scenarios of the DR strategy were assumed. A DR timeframe was assumed from 19:00 to 21:00 in the summer season. 
For each DR event day, the daily consumption profiles with 1-min intervals were retrieved for each household.

Subsequently, the durations of AC use in each target household during the DR timeframe were detected by the load sequences above a threshold level $\tau$ of $100 \mathrm{~W}$, which is defined to avoid the detection of the AC's selfcleaning process. In the case of the AC use duration during the DR timeframe, two DR scenarios were considered, as follows:

\section{Scenario 1: Maximum potential deferral}

In this scenario, the occupants were assumed to be $100 \%$ resigned to evaluate the maximum potential. The AC cooling load was allowed to be shifted afterwards only if the operation schedule of the cooling use coincided with the DR timeframe. The detected ACL would be shifted after the end of the DR timeframe with a minimum level of delay.

\section{Scenario 2: Activation based partial deferral}

In this scenario, the detected AC cooling load was partially shifted. The demand deferral only focused on the cooling usage events of the AC units that were switched from within the DR timeframe. The cooling load profiles would be shifted either forward or afterwards, depending on the time period between the exact time of the AC activation and boundaries of the DR timeframe. This scenario is effective in reducing the intensive demand caused by AC activation, which is more deferrable for load shifting because it usually lasts for less than an hour.

\subsection{Peak reduction potential}

The estimated potential of annual peak demand reduction for different ratios of engaged dwellings with the proposed 2 DR scenarios is shown in Fig. 8. The reduced annual peak load differs according to the different shares of the community households adopting the proposed DR scenarios. For the first scenario, where the maximum load shifting was targeted, a $4.92 \%$ reduction in the annual peak electricity demand was achieved. This optimistic effect is considered as a baseline case in this study. As expected, the peak reduction decreases with a decrease in the percentage of households involved. However, we can generally observe that the reduction potential of the annual peak load dropped at a lower rate compared to the ratio of involved households. For example, by involving households with more than $800-\mathrm{h}$ cooling hours into the proposed DR scenarios, a considerable reduction of $3.1 \%$ and $2.1 \%$ in the annual peak was achieved in the maximum and limited scenarios, respectively. This peak reduction was more than half of that in the baseline case, although the selected households accounted for only $23 \%$ of all the community users.

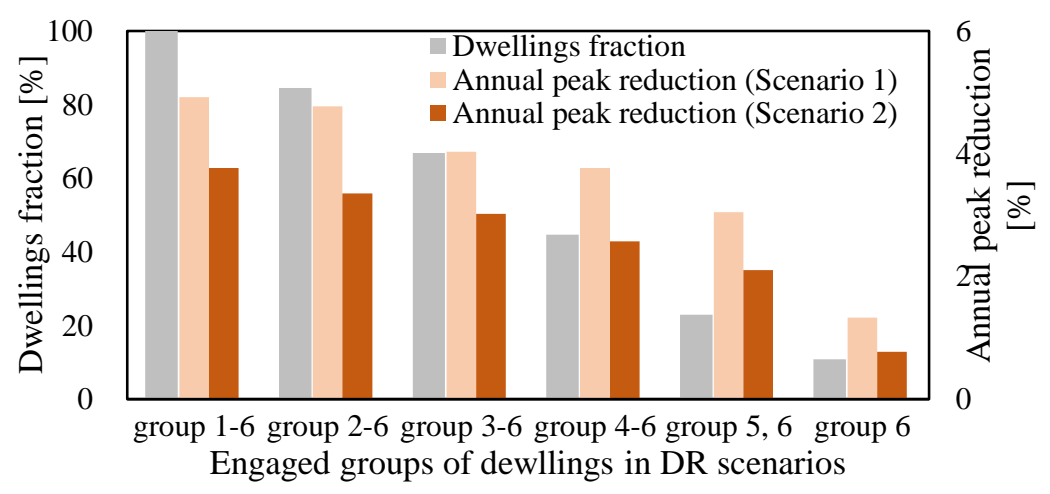

Fig. 8. Potentials of annual peak demand reduction for different ratios of engaged dwellings with the proposed two DR scenarios.

A similar conclusion can be drawn in Fig. 9, which is a scatter plot of deferrable peak air-conditioning load using scenario 2 in summer for different groups of households in the target community. The horizontal axis refers to the dwelling IDs sorted by their household cooling hours throughout summer season. Vertical axis indicates the amount of peak time electricity energy that can be shifted to other time period. As expected, the growing deferrable load amount with dwellings with more AC use hours clearly shows the relatively larger DR flexibility in more active users. Furthermore, the parabolic relation shown in this graph also indicates an increasing effectiveness of the proposed DR scenarios when more active AC users are involved.

These results indicate that the target of the demand reduction for a specific community can be achieved by identifying and recruiting a small portion of frequent users into appropriate DR strategies. Such conclusion can be especially applicable in AC use due to the larger potential of deferrable energy in peak time for active users. When applying such energy management strategies, specific fraction of AC users should be given prior attention for their engagement to achieve maximum effectiveness and benefits.

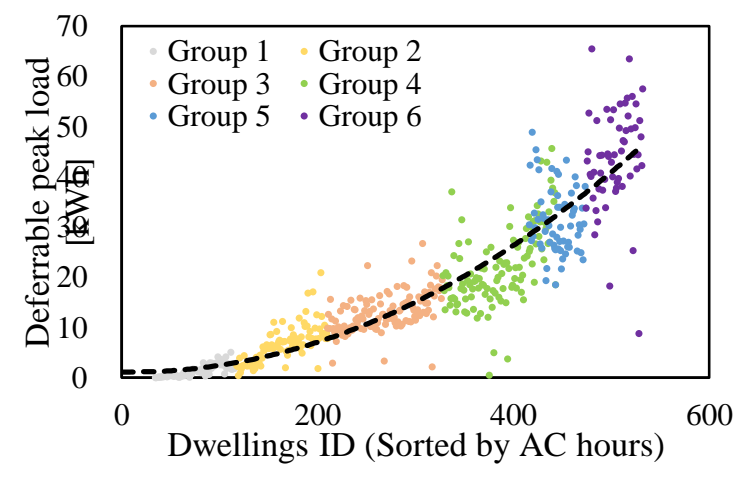


Fig.9. Scatter plot of deferrable peak air-conditioning load (using scenario 2) in summer for different household groups in target community.

\section{Conclusion and discussion}

The stochastic features and contribution of residential air conditioning loads to the total electricity demand were examined based on appliance-level energy data. The dataset was obtained from a residential building consisting of 586 dwelling units for one year. After processing the raw data, the statistical analysis of the ACL and household-level load revealed a significant contribution of ACL on the annual peak electricity demand of the community. Furthermore, the effectiveness of the two demand response scenarios, with maximum and limited deferral potential, were examined to assess the potential reduction in the annual peak demand. The target households were classified into six groups based on their dependence on AC cooling to evaluate the DR effectiveness with different participation ratios. The results indicate that a reduction of up to $4.9 \%$ can be achieved by applying the proposed DR strategy in the evaluated community. Additionally, considerable deferral and reduction were confirmed even with the engagement of a small portion of households by proper identification of target households that intensively use AC for a long time duration.

\section{References}

[1] Agency of Natural Resources and Energy, Energy White Paper 2019, June 2019.

[2] Tokyo Electric Power Company (TEPCO), Electricity Market in Japan, July 2004.

[3] Organization for Cross-regional Coordination of Transmission Operators, Outlook of electricity supply-demand and cross-regional interconnection lines: actual data for fiscal year 2017, December 2018.

[4] Enshassi Adnan, Residential Consumers' Attitudes towards Water and Energy Conservation, Proceedings of International Exchange and Innovation Conference on Engineering \& Sciences (IEICES). 3, pp. 47 - 52, 2017-10-19.

[5] Solli Murtyas, Occupancy Rate and Water Utility Effects on Energy Consumption of Commercial Building: Case Study Grand Inna Malioboro Hotel in Indonesia, Proceedings of International Exchange and Innovation Conference on Engineering \& Sciences (IEICES). 5, pp. 36 - 38, 2019-10-24.

[6] Proctor J, Proctor Engineering Group, Air Conditioning, Peak Demand, And Public Goods Funds, White Paper, March 2005.

[7] Rosenthal DH, Gruenspecht HK, Moran E. Effects of global warming on energy use for space heating and cooling in the United States. Energy J 1995;16(2):77-96.

[8] Scott MJ, Hadley DL, and Wrench LE. Effects of climate change on commercial building energy demand, Energy Sources 1994;16(3), 339-354.

[9] Fan H, MacGill IF, Sproul AB. Statistical analysis of drivers of residential peak electricity demand. Energy Build 2017;141:205-17.
[10] Drysdale B, Wu J, Jenkins N. Flexible demand in the GB domestic electricity sector in 2030. Appl. Energy 2015;139, 281-290.

[11] Kirschen DS. Demand-side view of electricity markets. IEEE Trans Power Syst 2003; 18(2):5207.

[12] Palensky P, Dietrich D. Demand side management: demand response, intelligent energy systems, and smart loads. IEEE Trans Ind Inf 2011;7(3):381-8.

[13] Malik A, Haghdadi N, MacGill I, Ravishankar J. Appliance level data analysis of summer demand reduction potential from residential air conditioner control. Appl Energy 2019;235:776-85.

[14] Yin R, et al. Quantifying flexibility of commercial and residential loads for demand response using setpoint changes. Appl Energy 2016;177:149-64.

[15] Zhang W, Lian J, Chang C, Kalsi K. Aggregated modeling and control of air conditioning loads for demand response. IEEE Trans Power Syst 2013;28(4): 4655-64.

[16] Kwac J, Rajagopal R. Data-driven targeting of customers for demand response. IEEE Trans Smart Grid 2016;7(5):2199-207.

[17] Cole WJ, Rhodes JD, Gorman W, Perez KX, Webber ME, Edgar TF. Community-scale residential air conditioning control for effective grid management. Appl Energy 2014;130:428-36.

[18] Koutitas G. Control of flexible smart devices in the smart grid. IEEE Trans Smart Grid 2012;3(3):133343.

[19] Xue X, Wang S, Sun Y, Xiao F. An interactive building power demand management strategy for facilitating smart grid optimization. Appl Energy 2014;116:297-310.

[20] Hu M, Xiao F. Investigation of the demand response potentials of residential air conditioners using greybox room thermal model. Appl Energy 2017;105(2017):2759-65.

[21] Chassin DP, Du P, Fuller JC. The potential and limits of residential demand response control strategies. In: 2011 IEEE power and energy society general meeting; 2011. p. 1-6. 